\title{
INTROSPECTION WITHOUT JUDGMENT
}

\author{
Anna Giustina (Institut Jean Nicod) \\ Forthcoming in Erkenntnis
}

\begin{abstract}
The focus of this paper is introspection of phenomenal states, i.e. the distinctively first-personal method through which one can form beliefs about the phenomenology of one's current conscious mental states. I argue that two different kinds of phenomenal state introspection should be distinguished: one which involves recognizing and classifying the introspected phenomenal state as an instance of a certain experience type, and another which does not involve such classification. Whereas the former is potentially judgment-like, the latter is not. I call them, respectively, reflective introspection and primitive introspection. The purpose of this paper is to argue that primitive introspection is a psychologically real phenomenon. I first introduce the distinction and provide some preliminary motivation to accept it ( $\$ 1)$. After some set-up considerations ( $(2)$, I present my central argument for the existence of a non-classificatory kind of introspective state (\$3), what I call the 'argument from phenomenal-concept acquisition'. Finally, I briefly present some reasons why my distinction may be important for various philosophical debates $(\$ 4)$.
\end{abstract}

The topic of this paper is introspection of phenomenal states. Introspection is often defined as a distinctively first-personal method through which one can get knowledge of, or form beliefs about, one's current conscious mental states. ${ }^{1}$ Through introspection we can form beliefs about our current perceptual, proprioceptive, bodily, and algedonic states, as well as about our current emotions, beliefs, thoughts, desires, etc. The narrower notion of introspection of phenomenal states, which is the focus of this paper, refers to the distinctively first-personal method through which one can form beliefs about the phenomenology of one's current conscious mental states. Call such beliefs phenomenal beliefs; then 'introspection of phenomenal states', as I use the expression here, is the distinctively first-personal method through which we form phenomenal beliefs. ${ }^{2}$

\footnotetext{
${ }^{1}$ Some opt for a broader notion of introspection, which includes recently past experiences (e.g. Schwitzgebel 2012) or unconscious attitudes (e.g. Nisbett and Wilson 1977) among its potential targets. Here I focus on the narrower notion presented in the main text.

2 The scope of introspection of phenomenal states partly depends on which conscious mental states have phenomenology. One example concerns cognitive states such as thoughts and occurrent beliefs. Whether these states can be the target of introspection of phenomenal states depends, at least partly, on one's stance about the existence and nature of cognitive phenomenology. Here I remain neutral on this point. For those who believe that there is cognitive phenomenology, what I say may apply to introspection of the phenomenology of cognitive states too.
} 
All and only the subject's current conscious states with phenomenology (i.e. states there is something it is like to be in) are potential targets of introspection of phenomenal states. Beliefs such as (would be expressed by) "I am feeling pain in my right knee" and "I am currently having a visual experience as of a red poppy" may be formed on the basis of introspection in this sense. Beliefs about unconscious states, non-phenomenal aspects of the experience ("My feeling pain in my right knee occurs on Thursday"), past or future experiences ("Yesterday I was quite nervous"), and others' inner life ("You are in love with her") cannot be formed (at least not solely) on the basis of introspection of phenomenal states.

Introspecting is something we can actively $d o$, a mental act we can perform. Much of the literature on introspection seems to assume that the product of such an introspective act is always an introspective judgment. Accordingly, the debate revolves around the nature (origin and content) and epistemic features (reliability, justification, possession of special epistemic properties such as infallibility and immediacy) of introspective judgments. Here I will argue that there exists a pre-doxastic product of introspective acts, a mental state without a propositional structure and a conceptual content more psychologically fundamental than introspective judgments. More precisely, I will argue that two different kinds of introspective state should be distinguished: one which involves recognizing and classifying the introspected phenomenal state as an instance of a certain experience type, and another which does not involve such classification. Whereas the former is potentially judgment-like, the latter is not. I call them, respectively, reflective introspection and primitive introspection. ${ }^{3}$

The purpose of this paper is to argue that primitive introspection is a psychologically real phenomenon. ${ }^{4}$ I first introduce the distinction and provide some preliminary motivation to accept it $(\$ 1)$. After some set-up considerations (\$2), I present my central argument for the existence of a non-classificatory kind of introspective state (\$3), what I call the argument from phenomenal-concept acquisition. Finally, I briefly present some reasons why my distinction may be important for various philosophical debates (\$4).

\section{TWO KINDS OF INTROSPECTION}

\subsection{A first pass}

Suppose you are tasting papaya and considering the gustatory experience you have while doing that. You know what papaya tastes like, therefore you can recognize a papaya-taste experience and distinguish it from other types of gustatory experience. When you attend to your current experience, then, you can recognize that experience as a papaya-taste experience. You thereby

\footnotetext{
3 Thanks to Susanna Schellenberg for suggesting the label 'primitive introspection' to me.

4 What I really believe is the stronger thesis that only primitive introspection is the immediate product of an introspective act (reflective introspection somehow depends on primitive introspection). However, arguing for this claim would require, beside the argument I present here, an account of the relationship between primitive introspection and reflective introspection, as well as an explanation of how and why one grounds the other, which clearly exceeds the scope of a single paper. I therefore grant that reflective introspection too can be the immediate product of an introspective act. In any case, this is only peripherally relevant to my present purpose, which is to defend the thesis that primitive introspection is one such immediate product.
} 
introspect that this experience you are having is a papaya-taste experience. Call this case (1). Now, suppose instead that you have never tasted papaya before, and unexpectedly bump into a papaya-taste experience (perhaps you are blindfolded and someone administers a papaya slice to you). In this case—call it case (2)—when you attend to your experience, you surely do not introspect that you are having a papaya-taste experience. You have no idea what papaya tastes like, so you cannot recognize your current experience as a papaya-taste experience. However, you can certainly introspect the weird gustatory experience you are having: you can introspect the experience even if you do not introspect that it is an instance of any particular experience type.

There is thus an important difference between the introspective state you have in (1) and the one you have in (2). In (1), you have a kind of introspective state which involves your recognizing the introspected phenomenal state and classifying it under a known experience type. Case (2) features a kind of introspective state that does not involve any such classification: there you simply attend to your experience's phenomenology, and thereby introspect it, without recognizing it or classifying it as an instance of any previously encountered experience type.

One may object that, even though in case (2) you cannot classify the experience you introspect as a papaya-taste experience, you can nevertheless classify it as an instance of other experience types. For example, you can classify it as a fruit-taste experience, or as a sweet-taste experience, or, at the very least, as a taste experience. And indeed, it may well be that, in case (2), you do introspect that this experience you are having is a fruit-taste experience, or that it is a sweettaste experience, or that that it is a taste experience. But consider now a modification of case (2); call it $\left(2^{*}\right)$. Here, not only you have never tasted papaya before-you have never tasted any fruit. Accordingly, you cannot classify what you introspect as a fruit-taste experience. Furthermore, you have never tasted sweet food before, so you cannot classify it as a sweet-taste experience either. In fact, you have never had any gustatory experience in your life before tasting this papaya, say because of a dysfunction in your taste buds from which you have just recovered. Thus, you cannot even classify this experience you are having as a taste experience. In $\left(2^{*}\right)$, then, not only you cannot introspect that your experience is a papaya-taste experience: there is no experience type such that you could classify your experience as an instance of it. Therefore, in $\left(2^{*}\right)$, you introspect your experience without classifying it.

I will argue that the introspective state you have in (1) is importantly different from that which you have in $\left(2^{*}\right)$. Indeed, I suggest, they are two radically different kinds of introspective state. I call the first kind reflective introspection and the second primitive introspection.

One may object that, even in case $\left(2^{*}\right)$, you could classify your experience as an instance of some experience type. Even if you cannot classify it as a gustatory experience, you certainly can classify it, say, as a non-visual experience, or as a non-auditory experience (provided that you have had visual or auditory experiences before). ${ }^{5}$ However, even if you do possess such a classificatory ability, you do not need to exercise it when you introspect: although you can classify your current experience as, say, non-visual, you do not need to so classify it in order to be introspectively aware of it. In fact, there are innumerable ways we could classify the experiences we introspect (as nonreddish, as non-pain, as non-itch, as non-hunger, as non-anger, and so on and so forth), most of which we do not actually exercise when we introspect (even when we reflectively introspect). As we will

\footnotetext{
5 Thanks to the anonymous referee for this objection.
} 
see in the next subsection, primitive introspection occurs independently of the subject's exercising the relevant classificatory ability—although it is compatible with the subject's possessing the relevant ability.

\subsection{Primitive introspection and reflective introspection}

The most fundamental difference between primitive introspection and reflective introspection is that, whereas the latter involves classifying what is introspected as an instance of a certain experience type, the former does not involve any such classification. Importantly, classification requires recognition: it implies recognizing that the introspected experience is of a certain known, previously encountered kind.

Merely possessing the ability to so classify what is introspected is not sufficient for reflective introspection: to reflectively introspect, one must exercise this ability. In contrast, primitive introspection is possible in the absence of any classificatory ability. To be sure, one may primitively introspect also in cases where one does possess the relevant classificatory ability. What is essential to primitive introspection is that the subject does not exercise that ability.

Arguably, the capacity to classify what is introspected as an instance of a previously encountered experience type is due to possession of the right concepts; more specifically, of the right phenomenal concepts. (Compare: the ability to classify something as a cat depends on the possession of the concept CAT.) For this reason, in what follows, the classificatory/nonclassificatory distinction will map onto the conceptual/non-conceptual distinction, where a mental state is conceptual iff it depends on the deployment of some concept(s), nonconceptual iff it does not depend on the deployment of any concept. ${ }^{6}$

A caveat is in order. There may be some phenomenal concepts whose deployment does not imply classification. Let pure phenomenal demonstratives be phenomenal concepts with no descriptive component: phenomenal demonstratives like THIS and THAT. These can be used to refer to an experience but, unlike descriptive demonstratives (such as THIS PAIN, Or THAT EXPERIENCE), are not accompanied by any description. Pure phenomenal demonstratives, by definition, do not involve any classification of the kind outlined above. Accordingly, if pure phenomenal demonstratives exist—an issue I do not intend to take a stand on heredeployment may be involved in primitive introspection.

A further exception may be made for what David Chalmers (2003) calls direct phenomenal concepts. These are phenomenal concepts that are formed upon attending to the experience itself, which (according to Chalmers) partly constitutes their content. Therefore, they are not possessed prior to introspecting the relevant experience. By definition, then, direct phenomenal concepts do not involve classifying the experience they are associated with as an instance of a previously encountered experience type. Again, I will not take a stand on whether there really are such

\footnotetext{
${ }^{6}$ By 'deploying' a concept I mean exercising it. 'Applying' a concept is a way to deploy it. When you imagine a unicorn, you may deploy the concept UNICORN, even though you do not apply it to anything. When you see a table, and recognize it as a table, you not only deploy the concept TABLE, but also apply it to what you see.
} 
concepts. If there are, then primitive introspection may involve the deployment of direct phenomenal concepts too.

What is fundamental to the distinction between primitive and reflective introspection, then, is that the former, unlike the latter, does not involve the deployment of any phenomenal concept already possessed by the subject prior to introspecting. Accordingly, reflective introspection is a conceptual introspective state, whereas primitive introspection is a nonconceptual introspective state, where an introspective state is conceptual iff it depends on the deployment of some phenomenal concept(s) already possessed by the subject prior to introspecting, nonconceptual iff it does not depend on the deployment of any phenomenal concept possessed by the subject prior to introspecting. On this characterization, the conceptual/nonconceptual distinction maps exactly onto the classificatory/non-classificatory distinction. $^{7}$

Note that primitive introspection being nonconceptual, it cannot be a propositional attitude. ${ }^{8}$ If propositions are 'made up' of concepts, the fact that primitive introspection is nonconceptual entails that it is non-propositional. Reflective introspection, in contrast, may be propositional, namely, if the concepts deployed while being in a state of reflective introspection are combined in the way required to form a structured proposition. You may introspect your headache experience as a headache experience (and thereby deploy the concept HEADACHE EXPERIENCE) without introspecting that this experience is a headache experience. In this case, you are in a non-propositional state of reflective introspection. However, from the descriptive phenomenal demonstrative THIS EXPERIENCE and the phenomenal concept HEADACHE EXPERIENCE you may also form the propositional content 'This experience is a headache experience'. Your state of reflective introspection would then be conceptual and propositional. For the purpose of this paper, distinguishing between conceptual but non-propositional and both conceptual and propositional states of reflective introspection is not of crucial importance. ${ }^{9}$

To recapitulate, reflective introspection requires the deployment of (some of) the phenomenal concept(s) that are associated with the introspected experience and are already possessed by the subject prior to introspecting: it involves recognizing the introspected experience as an instance of a certain experience type. Therefore, in order for you to reflectively introspect that your current conscious experience is F, you must possess the phenomenal concept F, and deploy it while introspecting. For example, in order for you to reflectively

\footnotetext{
${ }^{7}$ One may object that there is at least one concept which is already possessed by the subject prior to introspecting and is deployed while introspecting at all times: the concept EXPERIENCE. Now, for one thing, even if subjects who are capable of introspection typically possess the concept EXPERIENCE, that they necessarily deploy it when they introspect is arguable. Moreover, this objection does not seem very pressing, given the point I want to make here, i.e. that primitive introspection does not involve classifying what is introspected as an instance of any experience type. For when you deploy the concept EXPERIENCE, you classify your experience as an experience, but not as an instance of any more specific experience type.

${ }^{8}$ I assume that propositions are structured and have concepts as their constituents. On other views of propositions (Stalnakerian or Russellian, for example), the claim that primitive introspection is non-propositional may be false. As noted, what is most important for my distinction is that primitive introspection does not involve deployment of previously possessed phenomenal concepts.

9 Although this will be important for some developments of the work grounded in the distinction between primitive introspection and reflective introspection.
} 
introspect that your current experience is a headache experience, you must possess the concept HEADACHE EXPERIENCE and apply it to the experience you are introspectively attending to. Primitive introspection, in contrast, is nonconceptual. When you primitively introspect your current conscious experience, you need not possess any phenomenal concept and indeed no previously possessed phenomenal concept is applied when you merely primitively introspect (modulo the above discussion of putative pure phenomenal demonstratives and direct phenomenal concepts). So, to merely primitively introspect your headache experience, not only do you not need to possess the concept HEADACHE EXPERIENCE, even if you do possess that concept you must not deploy it. Of course, it is very likely that you know headache experiences well enough to be unable to introspect one without immediately recognizing it and thereby applying the concept HEADACHE EXPERIENCE to it. If so, then every time you primitively introspect your headache experience you also reflectively introspect that it is thus-and-so-you cannot merely primitively introspect it. (However, the two kinds of introspection may be distinguished even in cases in which one's experience is immediately recognized. For one thing, they may be discerned conceptually: for each state of reflective introspection, there is a state of primitive introspection that the subject could be in, had they not possessed the relevant phenomenal concepts.)

There is another prima facie consideration that supports the distinction between reflective and primitive introspection. When we introspect, we often seem to be able to distinguish phenomenal properties that are more fine-grained than the concepts at our disposal. But what can be grasped by reflective introspection is restricted to the phenomenal properties for which the subject has a concept. Therefore, when one reflectively introspects, one will often also primitively introspect, and by primitive introspection will grasp the details of the phenomenology of one's current experience that outstrip one's phenomenal concepts.

Having presented some preliminary considerations in its support, in the bulk of the paper I present a sustained argument for the existence of primitive introspection: I defend the thesis that some introspective states do not involve classifying what is introspected-that is, introspecting does not necessarily require recognizing what is introspected as an instance of a certain experience type. I call it the argument from phenomenal-concept acquisition. Before that, some set-up considerations are in order.

\section{PHENOMENAL CONCEPTS}

Phenomenal concepts, as conceived here, are concepts which are associated with the phenomenology of experience. They are personal-level mental representations that enable the subject to (i) distinguish the experience they are currently introspecting from other current or past experiences and (ii) recognize it as an instance of a certain experience type. To each kind of experience corresponds a distinct phenomenal concept: to pain experience corresponds the phenomenal concept PAIN, to phenomenal-red experience corresponds the phenomenal concept PHENOMENAL RED, to papaya-taste experience corresponds the phenomenal concept PAPAYATASTE EXPERIENCE, and so on. Phenomenal concepts may be more or less determinate: PHENOMENAL SCARLET is a determinate of the determinable PHENOMENAL RED, which is a determinate of COLOR EXPERIENCE, which is a determinate of VISUAL EXPERIENCE. 
Some phenomenal concepts are built up compositionally from other phenomenal concepts. ${ }^{10}$ The phenomenal concept EXCRUCIATING PAIN, for instance, is built up by composition from EXCRUCIATING and PAIN. Of these, PAIN is associated with a qualitative phenomenal property, where qualitative phenomenal properties are phenomenal properties which define the qualitative aspect that characterizes each kind of phenomenal state: they are that which constitutes the difference between, say, phenomenal-red experience and phenomenalblue experience, or between papaya-taste experience and stubbing-pain experience. ${ }^{11}$ On the other hand, EXCRUCIATING is associated with intensity, which is a quantitative phenomenal property. Thus the phenomenal concept EXCRUCIATING PAIN can be acquired compositionally by putting together a phenomenal concept for a qualitative phenomenal property and a phenomenal concept of a quantitative phenomenal property.

More generally, composite phenomenal concepts may be acquired compositionally from more component phenomenal concepts. Obviously, however, not all phenomenal concepts can be acquired in this way, on pain of infinite regress. There must be a layer of phenomenal concepts that are either not acquired at all or acquired non-compositionally.

Basic phenomenal concepts are phenomenal concepts which are not formed by composition from other concepts. They constitute the foundational layer out of which non-basic phenomenal concepts may be compositionally formed. ${ }^{12}$ Arguably, all phenomenal concepts associated with qualitative phenomenal properties are basic. Among these are concepts associated with perceptual experiences (PHENOMENAL RED, SOFTNESS EXPERIENCE, PAPAYATASTE EXPERIENCE, OLFACTORY EXPERIENCE, etc.), algedonic experiences (PLEASURE, PAIN, SORENESS, THROBBING, etc.), bodily sensations (ITCH, TICKLE, ORGASM, etc.), interoceptive sensations (HUNGER EXPERIENCE, FAST-HEARTBEAT EXPERIENCE, etc.), emotions (ANGER, FEAR, etc.), moods (EUPHORIA, DEPRESSION, etc.). It is plausible to think that phenomenal concepts of this kind constitute the foundational layer, for it is hard to find more basic phenomenal out of which they could be built up. However, this plausible assumption is not quite necessary for the argument of this paper. All that is necessary is that there be some foundational layer of phenomenal concept not compositionally acquired.

Acquiring a phenomenal concept means coming to possess it. One possesses a phenomenal concept iff one has it available to be deployed in cognition and action-guidance. Deploying a concept means using or exercising it, where exercising a concept is intended here as a personal-level process. Personal-level exercise of a concept involves active manipulation of the concept. Concept deployment is personal-level exercise of the concept in this sense. A phenomenal concept is innate just in case it is possessed but not acquired.

\footnotetext{
10 Provided that we assume a non-atomistic view of concepts. On a non-atomistic view, concepts can be built up compositionally from other concepts: BACHELOR, for instance, may be built up compositionally from UNMARRIED and MALE. On an atomistic view, instead, no concepts are composite.

11 Arguably, two qualitatively different phenomenal states (phenomenal states with different qualitative phenomenal properties) are phenomenal states of different kinds.

${ }^{12}$ On the atomistic view, all phenomenal concepts are basic.
} 


\section{THE ARGUMENT FROM PHENOMENAL-CONCEPT ACQUISITION}

Perhaps the most compelling reason to maintain that there must be a kind of introspective state which is nonconceptual (in the sense specified above) is that the acquisition of phenomenal concepts would be impossible otherwise. Roughly, the idea is the following. It is natural to think that we acquire phenomenal concepts by introspection. Now, if one's introspective state is conceptual, then one can only have it if one already possesses the concept(s) associated with what is introspected. If all introspective states are conceptual, then the possession of all phenomenal concepts must be prior to the possibility of introspecting. But if this is the case, then phenomenal-concept acquisition is mysterious. The full argument is much more complex, however, and must be developed more slowly. This is the purpose of the present section.

The argument just sketched partly retraces the argument from perceptual-concept acquisition for nonconceptualism about perceptual experience (Heck 2000; Peacocke 2001). A variant of the latter has been recently put forward by Adina Roskies (2008), who argues that conceptualism about perceptual content must be rejected because it entails an unacceptable version of nativism about perceptual concepts (the thesis that perceptual concepts are innate, i.e. are possessed without being acquired). Although it differs from hers in many respects, the argument I propose is partly inspired by Roskies'.

\subsection{The argument: first step}

Assuming that non-basic phenomenal concepts are acquired by composition from more basic phenomenal concepts, the focus of the present argument is the acquisition of basic phenomenal concepts, i.e. the phenomenal concepts which constitute the foundational layer out of which composite phenomenal concepts are formed. The general structure of the argument from phenomenal-concept acquisition is as follows:

(P1) (Almost) all basic phenomenal concepts are acquired.

(P2) For most basic phenomenal concepts, if they are acquired, they are acquired by introspection.

(P3) If all introspective states are conceptual, then it is not the case that most basic phenomenal concepts are acquired by introspection.

(C) Not all introspective states are conceptual.

A note on the quantifiers. What do I mean by '(almost) all'? Consider this toy model: if 'most' is defined as 'more than 50\%', then '(almost) all' should be read as 'equal or very close to $100 \%$ '. That would allow for a few phenomenal concepts being innate consistently with (P1) being true. I use these unusual quantifiers to protect the argument from certain eventualities inessential to its core idea.

Thus, denying $(P 1)$, as framed here, would entail a version of nativism about phenomenal concepts that would strike many of us as highly implausible. For if, as it seems to be, the foundational layer of basic phenomenal concepts includes very many concepts associated with qualitative phenomenal properties, such a foundational layer is quite large-it includes a great number of phenomenal concepts. Denying $(P 1)$ would thus entail that a great number of 
phenomenal concepts are innate. To be sure, plausible versions of nativism are defended in the philosophical and cognitive-science literature (e.g. Susan Carey (2009) core cognition theory). However, none of them implies that a great number of phenomenal concepts are possessed from birth. Indeed, all they imply is that a few conceptual representations are innate. ${ }^{13}$ That a newborn possesses a great number of phenomenal concepts would mean that they possess representations that enable them to (i) distinguish a great number of experiences from one another and (ii) recognize each of them as an instance of a certain experience type. I find this very implausible. Those who agree with me on this will accept that, even if a few phenomenal concepts may be innate, almost all of them must be acquired. At the very least, we may think of the central thesis of this paper as the following conditional: if radical nativism about phenomenal concepts (i.e. the theory according to which most basic phenomenal concepts are innate) is false, then not all introspective states are conceptual.

The next two subsections are aimed at defending (P2) and (P3). In $\$ 3.2 \mathrm{I}$ argue that for most basic phenomenal concepts, if $\mathrm{C}$ (i.e. the phenomenal concept associated with the phenomenal property $\mathrm{C}$ ) is an acquired phenomenal concept, then $\mathrm{C}$ is acquired by introspection of $\mathrm{C}$-experiences. In $\$ 3.3 \mathrm{I}$ argue that if $\mathrm{C}$ is to be acquired by introspection of $\mathrm{C}$-experiences, then the relevant introspection of $\mathrm{C}$-experiences must be nonconceptual.

\subsection{Defending (P2)}

In this subsection I argue that, even though some basic phenomenal concepts $C$ may be acquired on the basis of something other than introspection of C-experiences, there are reasons to think that not most of them are. Presumably, if a basic phenomenal concept $\mathrm{C}$ is acquired, but not through the introspection of C-experiences, then $\mathrm{C}$ is acquired either (i) through the introspection of other kinds of experiences, or (ii) on the basis of something other than introspection. In the reminder of this subsection, I argue that even if (i) and (ii) are live options for some basic phenomenal concepts, they are not for most of them.

It may seem that (i) can be straightforwardly ruled out. If $\mathrm{C}$ is acquired through introspection, then it is much more plausible that it is acquired through introspection of $\mathrm{C}$ experiences than that it is acquired through introspection of non-C-experiences. Plausibly, if the concept PAIN EXPERIENCE is acquired through introspection, it is acquired through introspection of pain experiences, rather than, say, coldness experiences. However, one might resist this line of argument by appeal to a Hume-inspired 'missing shade of phenomenal blue' objection. ${ }^{14}$ It might be argued that, even though one may acquire the phenomenal concept PHENOMENAL-BLUE 7 by introspecting bluish $\mathrm{h}_{7}$ experiences, one may also acquire it by introspecting bluish ${ }_{6}$ experiences and bluish $_{8}$ experiences plus extrapolation.

\footnotetext{
${ }^{13}$ The innate conceptual representations posited by core cognition are abstract in kind and limited in number. They belong to three domains: objects (including representations of causal and spatial relations), numbers, and agents (including representations of goals). Even though the latter domain may include some folk psychological concepts (goal, attentional state, etc.), core concepts surely do not include a great number of phenomenal concepts. Indeed, they only include a few (plausibly not more than $1 \%$ ).

14 Thanks to Andrew Lee and Emile Thalabard for drawing my attention to this objection.
} 
My reply to this objection is twofold. First, it is not straightforward that PHENOMENAL$\mathrm{BLUE}_{7}$ can be acquired by extrapolation. To be sure, what can be acquired by extrapolation is the description < the phenomenal color between phenomenal-blue ${ }_{6}$ and phenomenal-blue ${ }_{8}$ in the phenomenal-color spectrum $>$. However, that this description amounts to the phenomenal concept PHENOMENAL-BLUE 7 is far from evident. For one thing, I doubt that such a description alone would enable one to distinguish and recognize a bluish ${ }_{7}$ experience upon encounter. Second, even if phenomenal-concept acquisition by extrapolation were possible, it surely could not be the case that all or even most basic phenomenal concepts are acquired by extrapolation. ${ }^{15}$ Even if PHENOMENAL-BLUE 7 could be acquired by extrapolation from PHENOMENAL-BLUE 6 and PHENOMENAL-BLUE 8 , the latter would have to be acquired by introspection of bluish ${ }_{6}$ and bluish experiences respectively (if they were acquired by introspection at all). So even if some phenomenal concepts could be acquired via extrapolation, most phenomenal concepts surely cannot.

(ii) says that if a basic phenomenal concept $\mathrm{C}$ is acquired, it is acquired on the basis of something other than introspection. It seems to me that the most plausible way to defend (ii) is to adopt a sort of transparency theory of phenomenal-concept acquisition and maintain that basic phenomenal concepts are acquired on the basis of perceptual experience. On this view, basic phenomenal concepts are acquired not by attending to one's experience at all (thus not on the basis of introspection), but rather by attending to external objects and their properties. Phenomenal-concept acquisition therefore depends on some sort of perceptual process: it depends on the subject's perceptually representing their environment and their body. Plausibly, a transparency theorist of this sort would argue that by having certain perceptual experiences we acquire certain perceptual concepts and it is on the basis of the latter that basic phenomenal concepts are formed. So, for instance, the phenomenal concept PHENOMENAL RED is acquired on the basis of the perceptual concept RED, which in turn is acquired by the subject's having perceptual experiences as of red objects.

An immediate problem with this line of thought is that the order of acquisition between PHENOMENAL RED and RED is a traditionally highly controversial issue. The notion that PHENOMENAL RED is derived from RED, rather than the other way round, is not totally obvious. According to a long-standing tradition in philosophy, going back to Galileo, Descartes and Locke, colors are secondary qualities of objects. Unlike qualities such as shape, size, motion, and number (i.e. primary qualities), which are objective and defined independently of anyone's experience, secondary qualities are defined in terms of subjective responses and do not feature in the scientific explanation of reality. There are at least two contemporary versions of this traditional view. According to dispositionalism, colors are powers or dispositions to elicit in perceivers visual experiences of a certain type (see e.g. Johnston 1992, Peacocke 1984, and Levin 2000). ${ }^{16}$ A poppy is red in virtue of its having the power to cause reddish experiences in normal

\footnotetext{
${ }^{15}$ Nota bene: extrapolation is different from composition. That PHENOMENAL-BLUE 7 is acquired by extrapolation from PHENOMENAL-BLUE 6 and PHENOMENAL-BLUE 8 does not imply that PHENOMENAL-BLUE 7 is built up by composition from PHENOMENAL-BLUE 6 and PHENOMENAL-BLUE.

${ }^{16}$ Accordingly, color experience consists in representing objects as having the disposition to cause a certain type of experience (under standard conditions). For instance, an experience as of a red poppy consists in representing the poppy as having the disposition to cause a reddish experience (under standard conditions). Clearly, a prima facie
} 
subjects under normal conditions. According to projectivism, colors are not properties of external objects at all: strictly speaking, they are properties of visual fields. In color experience, properties of the visual field are erroneously represented as belonging to external objects-they are 'projected' to external objects (see Boghossian and Velleman 1989). On this view, a poppy is said to be red in virtue of the fact that when a subject sees the poppy, they erroneously attribute to it a property (the property of being red) which in fact belongs to a region of their visual field. On both versions of the secondary quality view, color properties are analyzed in terms of phenomenal-color properties. Color experience being more basic than color on this view, it would be natural to accompany it with an account of color concepts according to which color concepts are grounded in phenomenal-color concepts. Thus, if RED refers to the property of being disposed to elicit phenomenally red experiences under normal conditions, then, arguably, one will need to possess the concept PHENOMENAL RED prior to acquiring RED: one could not grasp the concept that refers to the external object's property without grasping the concept that refers to the experience caused by that property. Now, it is not my intention here to prove that phenomenal-color concepts are prior to color concepts. I am merely trying to highlight one substantial challenge our objector faces.

A second challenge is that even if the transparency account is viable for the acquisition of basic phenomenal concepts associated with perceptual experiences, it seems deeply problematic when it comes to other kinds of experiences, such as algedonic experiences (pain and pleasure), bodily sensations (such as tickles and itches), emotions, moods, and imagination. Indeed, the transparency theorist of phenomenal-concept acquisition is committed to four increasingly controversial claims concerning those experiences:

[1] All the experiences just listed are intentional.

[2] For each of these experiences, its phenomenal character is exhausted by its intentional content.

[3] Introspection of any of these experiences involves attending not to the experience itself, but to its intentional object.

[4] The phenomenal concepts associated with these experiences are acquired by attending not to the experience itself, but by attending to its intentional object.

Claims [1]-[3] have all met with fierce objections in the extant literature. Since considering them in detail exceeds the scope of one single paper, I will limit myself to listing some of those objections.

As for [1], consider algedonic experiences first. If it is now a widespread idea that what pain represents is some kind of bodily damage (Dretske 1995, Tye 1995a, Tye 1997), one may wonder what the intentional content of pleasure might be, since surely it does not seem to be some kind of bodily flourishing (Massin 2013). Bodily sensations such as tickles, itches, and orgasms are also often cited as counterexamples to [1] (Block 1995a and 1995b, for example, argues that orgasms are not intentional): there does not seem to be a straightforward way to determine what the intentional content of these states could be. On the representationalist side it has been argued that, for example, while having an orgasm "[w]hat one experiences, in part, is that

worry for dispositionalist accounts of color experience is circularity (cf. Boghossian and Velleman 1989). See Peacocke (1984) for a reply to this objection. 
something very pleasing is happening down there" (Tye 1995b: 269), and that that is the intentional content of an orgasm experience. On a plausible interpretation of the view, 'pleasing' means 'causing a pleasure experience'. However, first, although orgasm experiences clearly have pleasing features, they do not strike me as having the propositional content 'something causing a pleasure experience occurs down there; particularly, orgasms do not seem to have the metarepresentational feature that such an account would involve. ${ }^{17}$ Second, arguably, defining the intentional content of orgasms in terms of pleasure seems to require a prior definition of the intentional content of pleasure experiences which is not straightforward. Furthermore, defining an intentional content for moods has posed a particularly difficult challenge to defenders of [1] (Searle 1983). Even a hard-core representationalist like Dretske ends up admitting that the extent of the representationalist thesis may be somewhat limited by some "experiences - a general feeling of depression, for example_-about which I do not know what to say" (1995: xv).

On the representationalist side, efforts have been made to overcome the issues mentioned in the previous paragraph and defend the idea that all experiences have intentional content. Moods, for instance, are sometimes said to be intentional states directed to the entire world, or to any object one may happen to experience (see e.g. Solomon 1976). However, even if suitable intentional contents can be found for all the types of experience listed above, that their phenomenal character is exbausted by such contents, as required by [2], is even more controversial. For one thing, there are some aspects of algedonic and emotional experience that do not seem to fit smoothly that sort of reductive representationalist account, for example their affective or evaluative component (Aydede and Fulkerson 2014). Moods especially seem to escape a representationalist reduction. A case against representationalism about moods is put forward by Kind (2014), who argues that although moods may have intentional content, their phenomenology is too rich to be fully captured by their intentional content. Moreover, she claims, the phenomenal character of moods and their intentional content can vary independently of one another (Kind 2014: 124-129). ${ }^{18}$

As for [3], a vast critical literature has been produced against it (Block 1996, Kind 2003, Loar 2003, Siewert 2004). Indeed, various arguments in defense of the claim that introspection involves attending to one's experience have been provided (Goldman 2006, Petitmengin 2006, Hill 2009, Siewert 2012). As an example, consider moods again. The transparency of experience thesis predicts that, when you are, say, in an elated mood, and you introspect your elation, your attention is directed not to the experience you have, but rather to some external object, or perhaps to some bodily states. Yet, this does not seem to be the case. As Kind points out, "[i]n attending to my experience of elation, it seems most natural to describe what I'm attending to as the elation itself. I'm not simply attending to some feature of a changing series of things, or even to some unbound feature. Rather, I focus directly on what it feels like to be elated” (2014: 130).

\footnotetext{
${ }^{17}$ For an alternative objection, see Block (1996: 33): "I can have an experience whose representational content is that my partner is having a very pleasing experience down there that changes in intensity, and although that may be pleasurable for me, it is not pleasurable in the phenomenally impressive way that graces my own orgasms."

18 Kind's argument focuses in particular on variations in phenomenal intensity that have no plausible intentional correlates.
} 
To my knowledge, there are no direct arguments against (or for) [4] in the extant literature. However, if credence in either of [1]-[3] is weakened by the arguments mentioned above, so will be that in [4]. Moreover, there seem to be independent reasons to reject [4]. Except perhaps perceptual experiences, it seems much more plausible that the concepts we use to think about our experiences are formed by attending to properties of the experience itself, rather than to what the experience is about. Thinking introspectively (or making an introspective judgment) about the anger I feel is different both from thinking (making a judgment) about the person who causes my anger experience and from thinking (making a judgment) about the bodily states that accompany my anger. ${ }^{19}$ When I think that my anger experience is intense, my thought makes no reference to the person who causes my anger or to any of my current bodily states. Accordingly, it seems much more plausible that the concept ANGER EXPERIENCE is acquired by attending to the anger phenomenology itself, rather than to the cause of the anger or some bodily states: it would be weird if we thought about the properties of our experiences through concepts that were originally formed by attending to something other than phenomenal properties.

Similar observations apply to moods like euphoria or depression. Even accepting that they are intentional states directed at the whole world, "casting happy glows or somber shadows on every object and incident of our experience", as Solomon (1976: 173) writes, it seems that thinking about one's depressive mood is different from thinking about the objects in one's environment as shrouded in "somber shadows". When I think about my depressive mood, it is the bad way I feel I think about, not the things around me. It may be that when I feel depressed I also have characteristic thoughts about my surroundings (that this object is pointless, that that person does not care about me, etc.). But, although they may be related to my depressive mood (perhaps partly caused by it), those thoughts are not about it. Accordingly, it is much more plausible that the phenomenal concept associated with depressive mood is acquired by attending to the depressive experience itself, rather than to objects in one's environment.

Moreover, it seems to me that one could acquire the concept DEPRESSIVE EXPERIENCE from inside a dark room, having perceptual experience of no object at all, simply by attending to the way one currently feels.

To repeat, it is not my purpose here to establish that a transparency account of phenomenal-concept acquisition is hopeless. I am merely trying to highlight the considerable challenges a transparency account of phenomenal-concept acquisition faces. To defend such an account, not only should it be established that [1], [2], and [3] are true of all phenomenally conscious experiences. It should also be shown that all phenomenal concepts are acquired by attending not to experience itself, but to its intentional objects. I hope to have shown, at the very least, that quite a lot of work should be done to make such an account viable for the acquisition of all basic phenomenal concepts, and that, indeed, there is a considerable number of basic phenomenal concepts such that a transparency account of their acquisition does not seem antecedently plausible (including concepts for algedonic, bodily, emotional and mood phenomenal properties). Since, however, the fate of transparency is not my topic here, I am

19 These correspond to the two main representationalist accounts of emotional phenomenology. See e.g. Prinz (2004). 
happy to withdraw to an overall thesis of conditional form: unless a viable transparency account of the acquisition of all phenomenal concepts is provided, there is reason to believe that some introspective states are nonconceptual.

Besides the radical transparency view just discussed, there is another option my objector may consider in defense of (ii) - i.e. the claim that if a basic phenomenal concept $\mathrm{C}$ is acquired, it is acquired on the basis of something other than introspection. It might be argued that, to acquire basic phenomenal concepts, introspecting one's experience is not required: all one needs is baving the relevant experience. So, for instance, to acquire the phenomenal concept PAPAYATASTE EXPERIENCE, all one needs is to have a papaya-taste experience-one does not need to introspect the experience. Accordingly, basic phenomenal concepts are (typically) acquired not via introspection but via the having of the experience. ${ }^{20}$

The difference between having and introspecting an experience consists, at the very least, in the fact that the latter but not the former involves attending to the experience. As noted in the introduction, introspection is something we actively do, a mental act we perform. Therefore, it does not occur automatically but requires an effortful and voluntary act on the part of the subject. Such an act partly consists in the subject's drawing their attention to the experience. Merely having the experience, in contrast, does not require any effort or voluntarily act and can occur independently of the subject's attending to the experience. ${ }^{21}$

As noted, acquiring a phenomenal concept $\mathrm{C}$ entails (a) coming to have a representation of the experience $\mathrm{C}$ which must (b) enable the subject to distinguish $\mathrm{C}$ from other experiences and recognize it as an instance of the C-experience type and (c) be available to be deployed by the subject in cognition and action-guidance. Now, for one thing, that merely having a conscious experience implies forming a representation of it is controversial. On first-order representationalism about consciousness (Dretske 1995, Tye 1995a), for example, having a conscious experience entails representing things in one's environment, but it does not entail representing the experience itself. On this view, then, having an experience is not sufficient for having a representation of it-therefore it is not sufficient for acquiring a phenomenal concept of the experience.

There are, however, other theories of consciousness-e.g., higher-order representationalism (Rosenthal 1997, Lycan 1996) and self-representationalism (Kriegel 2009)_ that do imply that having a conscious experience entails having a representation of it. These theories-different from first-order representationalism—-thereby fulfill (a). However, whether they fulfill (b) and (c) is debatable. To acquire the phenomenal concept $\mathrm{C}$, a subject must form a representation of the right kind: the representation must enable the subject to distinguish and recognize C-experiences. Yet, it seems that merely having an experience is not enough for the subject to subsequently be able to distinguish and recognize an experience of the same kind. ${ }^{22}$

\footnotetext{
${ }^{20}$ I owe this objection to the anonymous referee.

${ }^{21}$ Unless we adopt a view, such as Prinz's (2011), on which an experience can only be conscious if it is attended to. On views of this kind, the notion of having an experience collapses into the notion of introspecting an experience (as conceived here).

${ }^{22}$ Defenders of the HOT theory of consciousness (Rosenthal 1997) might disagree. The higher-order representation being a thought, on this view, it is propositional and conceptual and thereby allows for recognition. However,
} 
Imagine you are an aspiring sommelier. Arguably, part of your aspiration is to acquire a great number of fine-grained wine-taste-associated phenomenal concepts, i.e., phenomenal concepts that enable you to distinguish and recognize taste experiences associated with a great number of different types of wine. To achieve this result, for any wine-taste experience you want to acquire a concept of, you need to gain and store information about its phenomenology. Quite obviously, merely drinking a large variety of wines (and thereby having taste experiences associated with many different types of wines) is not sufficient to accomplish this task. (If the task were so easy to accomplish, I myself would be an expert sommelier by now.) The information-gaining-andstoring process required for wine-taste phenomenal-concept acquisition is an effortful and deliberate activity, which involves your directing and focusing your attention to each wine-taste experience. More generally, for you to acquire a representation that enables you to distinguish and recognize C-experiences, you must not only have a $\mathrm{C}$-experience, but also attend to, and thereby introspect it.

For similar reasons, the mere having of an experience is not enough to satisfy (c). As noted, possessing a concept requires it being available for personal-level deployment in cognition and action-guidance. Accordingly, a subject possesses a phenomenal concept C only if they can actively and deliberately retrieve it and manipulate it to form thoughts about the experience $\mathrm{C}$ and take decisions for action based on those thoughts. But merely having an experience is not enough to gain such personal-level cognitive access. ${ }^{23}$ Gaining personal-level cognitive access requires the subject's actively collecting information about the phenomenology of the relevant experience, which in turn, as noted, requires attending to and thereby introspecting the experience.

In sum, the mere having of an experience $C$ is not enough to acquire the phenomenal concept $\mathrm{C}$. To acquire a mental representation of $\mathrm{C}$ which enables the subject to distinguish and recognize $\mathrm{C}$-experiences and which is available to be deployed in cognition and action-guidance, the subject must introspect $\mathrm{C}$.

\subsection{Defending (P3)}

In the previous subsection, I have argued that, except perhaps for phenomenal concepts associated with perceptual experiences (for which a transparency account may be plausible), it is plausible to suppose that if a basic phenomenal concept $\mathrm{C}$ is acquired, then it is acquired by introspecting C-experiences. In this subsection, I argue that if all introspective states were conceptual, then no phenomenal concept $\mathrm{C}$ could be acquired by introspecting $\mathrm{C}$-experiences.

arguably, the HOT theory faces a similar challenge to that faced by conceptualism about introspection, i.e. that of explaining phenomenal-concept acquisition. Plausibly, to acquire a phenomenal concept $\mathrm{C}$ one must, at the very least, have a conscious $\mathrm{C}$-experience. But if having a conscious $\mathrm{C}$-experience requires possessing $\mathrm{C}$ (i.e. the phenomenal concept that partly constitutes the unconscious thought that makes a C-first-order representation conscious), it is mysterious how we come to possess phenomenal concepts at all. I thus would not recommend my objector to take the HOT theory as a basis for the claim that phenomenal concepts can be acquired via the mere having of an experience.

${ }^{23} \mathrm{My}$ reflection on this point has benefitted from conversation with Luca Gasparri. 
Conceptualism about introspective states therefore entails an implausible version of nativism according to which most basic phenomenal concepts are innate.

An introspective state's being conceptual implies that one cannot have it without deploying some (already possessed) concept(s). If introspecting a C-experience depends on the deployment of some phenomenal concept(s), then it depends either on the deployment of $\mathrm{C}$ (i.e. the phenomenal concept associated with the phenomenal property $\mathrm{C}$ ) or on the deployment of some phenomenal concept other than C (tertium non datur). Accordingly, if the content of all introspective states is conceptual, for any phenomenal concept $\mathrm{C}$, if $\mathrm{C}$ is acquired by introspection, then either ( $\mathrm{i}$ a $\mathrm{C}$ is acquired by introspecting $\mathrm{C}$-experiences, where introspecting a C-experience depends on the subject's deploying the concept $\mathrm{C}$, or (ib) C is acquired by introspecting C-experiences, but where introspecting a C-experience depends on the subject's deploying some concept other than C.

Now, there is no C for which (ia) can be an option. For if introspecting C-experiences depends on the subject's deploying $\mathrm{C}$, then $\mathrm{C}$ must already be possessed by the subject in order for them to introspect the experience. The point is that if the ability to have an introspective state depends on deployment of a certain concept, then that concept must be possessed by the subject prior to having the relevant introspective state. Accordingly, it cannot be acquired by way of that very introspective state.

What about (ib)? If introspecting C-experiences requires the deployment of some phenomenal concepts, but does not depend on the subject's deploying $\mathrm{C}$, then it depends on the subject's deploying some concepts $F_{1}, \ldots, F_{n}$ different from C. Accordingly, acquiring $C$ by introspecting $\mathrm{C}$-experiences would require that the content of $\mathrm{C}$ be built up by composition from other introspective concepts $F_{1}, \ldots, F_{n}$. If, for instance, the concept PAIN were acquired by introspecting pain experiences and pain experiences depended on the subject's possessing some concepts other than PAIN, then the acquisition of PAIN would depend on composition of those other concepts.

However, although it may be an option for some phenomenal concepts, (ib) is not an option for the phenomenal concepts under consideration here, namely basic phenomenal concepts (for basic phenomenal concepts, by definition, are not built up by composition form other concepts).

Moreover, a conceptualist theory according to which introspecting a C-experience depends on the subject's deploying some concept different from C strikes me as pointless. The whole point of maintaining that introspecting an itch experience depends on the subject's deploying some concept is, plausibly, that it depends on the subject's deploying the concept ITCH. The idea is that one cannot introspect an itch experience unless one can distinguish it from non-itch experiences and recognize it as an itch experience. Why should one maintain that introspecting an itch experience depends on the subject's recognizing their experience as something other than an itch?

So, even if some phenomenal concepts can be acquired by composition, the foundational layer of non-compositionally acquired phenomenal concepts still has to include a great number of introspectively-acquired concepts, whose acquisition cannot be accounted for in a 
conceptualist framework. For all I am arguing here, there may well be many phenomenal concepts acquired by composition of more basic phenomenal concepts-as long as the foundational phenomenal concepts, from which the others are compositionally acquired, are themselves acquired through a nonconceptual form of introspection (what I have called primitive introspection). There are only two alternatives: either the great number of foundational-layer phenomenal concepts are innate, as the nativist maintains, or they are acquired on the basis of perceptual concepts, as the transparency theorist suggests. But as I have already argued, neither option is very promising for a large swath of phenomenal concepts. On the one hand, it is implausible to maintain that a wailing newborn already possesses the concept ELATION EXPERIENCE. At the same time, even if the transparency theory is plausible for phenomenal concepts associated with perceptual experiences, again it is hard to see how concepts such as ELATION EXPERIENCE and ANGER EXPERIENCE could be acquired by composition of perceptual concepts like RED, SWEET, or RASPY.

I conclude that, if radical nativism and the radical transparency account of phenomenal-concept acquisition are to be avoided, then for many introspective concepts $\mathrm{C}$, C must be acquired by introspecting C-experiences. On a conceptualist framework, there is no viable way in which such concepts may be acquired. If we are to deny that they are innate, and if we agree that the transparency account of phenomenal-concept acquisition outlined in \$3.2 is implausible, we must accept that they are acquired with the aid of a nonconceptual form of introspection-primitive introspection.

\section{CONCLUSION: THE PHILOSOPHICAL SIGNIFICANCE OF PRIMITIVE INTROSPECTION}

I hope to have provided some good reasons to accept the idea that primitive introspection is a psychologically real phenomenon. I believe that primitive introspection is of non-negligible philosophical significance and that taking it into account would help shed light on various philosophical issues. In this final section, I briefly sketch some of the potential philosophical applications of the distinction between primitive introspection and reflective introspection.

First, the distinction can help address skepticism about the justification of phenomenal beliefs. It is sometimes argued that, since we are very often mistaken or uncertain about the phenomenology of our experiences, introspection is unreliable (see e.g. Schwitzgebel 2011). Skeptical arguments are grounded in the following reasoning: phenomenal beliefs are typically grounded in introspection; but introspection is unreliable; therefore, phenomenal beliefs are not reliably formed and thus not justified. The distinction between primitive and reflective introspection may shed light on the scope of this kind of skeptical arguments. In particular, it may help draw a diagnosis of why and how error or uncertainty occurs. Very roughly, the idea would be that error and uncertainty, if they occur, are not due to a flaw in primitive introspection, but rather to a misapplication of concepts on the part of the subject. If so, then the real target of skeptical arguments is only reflective introspection: the reliability of primitive introspection is left untouched. 
Second, suppose error and uncertainty are really as widespread as some skeptics imply. Then if error and uncertainty are due to misapplication of concepts, rather than to a flaw in primitive introspection, then this leaves open the possibility of their being reduced. The idea is that error and uncertainty can be avoided if our categorizing abilities are improved. Consider the following analogy. If the visual system of a subject does not work correctly, then not only the subject does not, but they also cannot, form correct visual judgements. On the other hand, it might occur that a subject typically forms wrong visual judgements not because of a malfunction in their visual system, but because they fail to correctly apply visual concepts to what they (reliably) see. In the latter case error can be corrected without correcting the subject's visual apparatus. If the subject had learned how to correctly apply visual concepts, they would be in a position to typically form correct visual judgements. Analogously, in the case of introspection, a subject may not typically form correct judgements about their conscious experience either because their faculty of primitive introspection is unreliable, or because their ability to recognize and classify the type of experience they are primitively introspecting is not sufficiently developed. Whereas in the former case the subject's introspective judgements are difficult to correct, in the latter case they are corrigible upon training, i.e. if the subject learns how to correctly apply phenomenal concepts.

Third, in light of the distinction, some special epistemic properties traditionally attributed to introspection, and now almost unanimously discarded, may be reconsidered for primitive introspection only. Consider infallibility. Although reflective introspection is clearly fallible, that primitive introspection is fallible as well is not so obvious. For if introspective error turned out to be always due to misapplication of concepts, then primitive introspection would turn out to be, in itself, immune to error. Again, the tenability of such a thesis is not straightforward and would require thorough argumentation. ${ }^{24}$ What I want to point out here is simply that keeping the distinction between primitive introspection and reflective introspection in mind may make us think these traditional questions under a different light.

Finally, investigating the relationship between primitive introspection and reflective introspection might be useful for an account of immediate justification and a defense of a version of traditional foundationalism. One might argue that foundational beliefs are phenomenal beliefs formed directly on the basis of, and immediately justified by, primitive introspection. Providing a satisfactory account of this phenomenal-belief formation process is far from easy. However, primitive introspection might turn out to be the right kind of state in which such an account could be grounded.

In this paper, however, I have not argued for any particular consequence of primitive introspection. I have restricted myself to the more basic task of arguing for the existence of primitive introspection, that is, the existence of a nonconceptual form of introspection that does not involve recognizing and classifying the introspected phenomenal state as an instance of any

\footnotetext{
${ }^{24}$ For one thing, infallibility is usually defined as a property of judgments. Primitive introspection being nonpropositional, the most ambitious thesis one could defend in this respect is that primitive introspection possesses a property which is analogous to infallibility but which applies to non-propositional states. Thanks to Andrew Lee for making this clear in my mind.
} 
experience type. If nothing else, this is important for a correct appreciation of the kinds of abilities and processes our conscious mind exhibits. ${ }^{25}$

25 This work was supported by the French National Research Agency's grants ANR-10-IDEX-0001-02 PSL and ANR-10-LABX-0087 IEC. For extensive comments to previous drafts, I am extremely grateful to Uriah Kriegel, long and numerous conversations with whom made a fundamental contribution to this paper. I am also grateful to David Chalmers, Jim Pryor, Charles Siewert, and Andrew Lee for their comments to a previous draft. I have benefitted from presenting parts of this paper at the Doc'in Nicod (IJN, Paris) and at the Washington Square Circle (NYU). I am grateful to the audiences there, and especially to François Recanati, Michael Murez, Luca Gasparri, Paul Egré, Enrico Terrone, Andrew Lee, Dan Hoek, Chris Scambler, Arden Koehler, Alma Barner, and Ben Holguin. The paper benefitted also from being presented at the "Consciousness and Introspection" seminar at the Université Paris-Sorbonne (Paris), at the "Introspection and Self-Knowledge" seminar at the Université de Lille 3 (Lille), at the PLM4 conference at the Ruhr University (Bochum), and at the "Introspection Sucks!" workshop at the University of Antwerp. I am grateful to the audiences there and particularly to Pascal Ludwig, François Kammerer, Matthias Michel, Emile Thalabard, Arnauld Dewalque, Denis Seron, Bertille de Vlieger, Michele Palmira, Tobias Schlicht, Sascha Fink, Manuel Martínez Merino, Bence Nanay, Adriana Renero, Katia Samoilova, Kranti Saran, and Eric Schwitzgebel. 


\section{REFERENCES}

Aydede, M., and Fulkerson, M. (2014). Affect: Representationalists' Headache. Philosophical Studies 170, 175-198.

Block, N. (1995a). How many concepts of consciousness? Behavioral and Brain Sciences 18, 272-287.

Block, N. (1995b). On a Confusion About a Function of Consciousness. Behavioral and Brain Sciences 18, 227-247.

Block, N. (1996). Mental Paint and Mental Latex. Philosophical Issues 7, 19-49.

Boghossian, P.A., and Velleman, J.D. (1989). Colour as a Secondary Quality. Mind 98, 81-103.

Carey, S. (2009). The Origin of Concepts (Oxford; New York: Oxford University Press).

Chalmers, D.J. (2003). The Content and Epistemology of Phenomenal Belief. In Consciousness:

New Philosophical Perspectives, Q. Smith, and A. Jokic, eds. (Oxford; New York: Oxford University Press), pp. 220-272.

Dretske, F. (1995). Naturalizing the Mind (Cambridge, MA: MIT Press).

Goldman, A.I. (2006). Simulating Minds: The Philosophy, Psychology, and Neuroscience of Mindreading (Oxford: Oxford University Press).

Heck, R.G. (2000). Nonconceptual Content and the "Space of Reasons." The Philosophical Review 109, 483-523.

Hill, C.S. (2009). Consciousness (Cambridge: Cambridge University Press).

Johnston, M. (1992). How to speak of the colors. Philosophical Studies 68, 221-263.

Kind, A. (2003). What's so Transparent about Transparency? Philosophical Studies 115, 225244.

Kind, A. (2014). The Case against Representationalism about Moods. In Current Controversies in Philosophy of Mind, U. Kriegel, ed. (London; New York: Routledge), pp. 113-134.

Kriegel, U. (2009). Subjective Consciousness: A Self-Representational Theory (Oxford: Oxford University Press).

Levin, J. (2000). Dispositional Theories of Color and the Claims of Common Sense. Philosophical Studies 100,151-174.

Loar, B. (2003). Transparent Experience and the Availability of Qualia. In Consciousness: New Philosophical Perspectives, Q. Smith, and A. Jokic, eds. (Oxford; New York: Oxford University Press), pp. 77-96.

Lycan, W.G. (1996). Consciousness and Experience (Cambridge, MA: MIT Press).

Massin, O. (2013). The Intentionality of Pleasures and other Feelings, a Brentanian Approach. In Themes from Brentano, D. Fisette, and G. Fréchette, eds. (Amsterdam: Rodopi), pp. 307-337.

Nisbett, R.E., and Wilson, T.D. (1977). Telling more than we can know: Verbal reports on mental processes. Psychological Review 84, 231-259.

Peacocke, C. (1984). Colour concepts and colour experience. Synthese 58, 365-381.

Peacocke, C. (2001). Does Perception Have a Nonconceptual Content? The Journal of Philosophy 98, 239-264.

Petitmengin, C. (2006). Describing one's subjective experience in the second person: An interview method for the science of consciousness. Phenomenology and the Cognitive Sciences 5, 229-269. 
Prinz, J. (2004). Gut Reactions: a Perceptual Theory of Emotion (Oxford: Oxford University Press).

Prinz, J. (2011). Is Attention Necessary and Sufficient for Consciousness? In Attention: Philosophical and Psychological Essays, Christopher Mole, Declan Smithies, and Wayne Wu, eds. (Oxford: Oxford University Press), pp. 174-203.

Rosenthal, D.M. (1997). A Theory of Consciousness. In The Nature of Consciousness: Philosophical Debates, Ned Block, Owen J. Flanagan, and Güven Güzeldere, eds. (Cambridge, MA: MIT Press), pp. 729-53.

Roskies, A.L. (2008). A New Argument for Nonconceptual Content. Philosophy and Phenomenological Research 76, 633-659.

Schwitzgebel, E. (2011). Perplexities of Consciousness (Cambridge, MA: MIT Press).

Schwitzgebel, E. (2012). Introspection, What? In Introspection and Consciousness, D. Smithies, and D. Stoljar, eds. (Oxford: Oxford University Press), pp. 29-48.

Searle, J. (1983). Intentionality: An Essay in the Philosophy of Mind (Cambridge; New York: Cambridge University Press).

Siewert, C. (2004). Is Experience Transparent? Philosophical Studies 117, 15-41.

Siewert, C. (2012). On the Phenomenology of Introspection. In Introspection and Consciousness, D. Smithies, and D. Stoljar, eds. (Oxford: Oxford University Press), pp. $129-168$.

Solomon, R.C. (1976). The Passions (New York: Anchor Press/Doubleday).

Tye, M. (1995a). Ten Problems of Consciousness: A Representational Theory of the Phenomenal Mind (Cambridge, MA: MIT Press).

Tye, M. (1995b). Blindsight, Orgasm, and Representational Overlap. Behavioral and Brain Sciences 18, 268-269.

Tye, M. (1997). A Representational Theory of Pains and their Phenomenal Character. In The Nature of Consciousness: Philosophical Debates, N. Block, O.J. Flanagan, and G. Güzeldere, eds. (Cambridge, MA: MIT Press), pp. 329 - 340. 